\title{
Beyond a "woman's problem": The role of relationship processes in female genital pain
}

Natalie O. Rosen, Ph.D. ${ }^{1,2}$, Kate M. Rancourt, B.Sc. ${ }^{1}$, Serena Corsini-Munt, M.A. ${ }^{3}, \&$ Sophie Bergeron, Ph.D. ${ }^{3}$

\footnotetext{
${ }^{1}$ Department of Psychology and Neuroscience, Dalhousie University, Halifax, Nova Scotia

${ }^{2}$ Department of Obstetrics and Gynaecology, IWK Health Centre, Halifax, Nova Scotia

${ }^{3}$ Department of Psychology, Université de Montréal, Montreal, Quebec
}

Corresponding Author: Natalie Rosen, PhD, Department of Psychology and Neuroscience, Dalhousie University, Life Sciences Centre, 1355 Oxford Street, P.O. Box 15000, Halifax, Nova Scotia B3H 4R2, Canada. Tel: 902-494-4044; Fax: 902-494-6585; E-mail: nrosen@dal.ca

Kate Rancourt, BSc, Department of Psychology and Neuroscience, Dalhousie University, Life Sciences Centre, 1355 Oxford Street, P.O. Box 15000, Halifax, Nova Scotia B3H 4R2, Canada. Tel: 902-494-4223; Fax: 902-494-6585; E-mail: kate.rancourt@dal.ca

Serena Corsini-Munt, MA, Department of Psychology, Université de Montréal, Pavillon MarieVictorin, C. P. 6128 succursale Centre-ville, Montreal, Quebec H3C 3J7, Canada. Tel: 514-3436111 Ext 37428; Fax: 514-343-2285; E-mail: serena.corsini-munt@umontreal.ca

Sophie Bergeron, PhD, Department of Psychology, Université de Montréal, Pavillon MarieVictorin, C. P. 6128 succursale Centre-ville, Montreal, Quebec H3C 3J7, Canada. Tel: 514-3436111 Ext 5353; Fax: 514-343-2285; E-mail: sophie.bergeron.2@umontreal.ca 


\begin{abstract}
Female genital pain is a prevalent condition that can disrupt the psychosexual and relational well-being of affected women and their romantic partners. Despite the intimate context in which the pain can be elicited (i.e., during sexual intercourse), interpersonal correlates of genital pain and sexuality have not been widely studied in comparison to other psychosocial factors. This review describes several prevailing theoretical models explaining the role of the partner in female genital pain: the operant learning model, cognitive-behavioural and communal coping models, and intimacy models. Empirical research on the interpersonal and partner correlates of female genital pain and the impact of genital pain on partners' psychosexual adjustment are reviewed. Together, this research highlights a potential reciprocal interaction between both partners' experiences of female genital pain. Future theoretical, methodological, and clinical research directions are discussed, which may enhance understanding of the highly interpersonal context of female genital pain.
\end{abstract}

Keywords: genital pain; vulvodynia; provoked vestibulodynia; genito-pelvic pain; pain; dyspareunia; romantic relationships; partners; intimacy; attachment; partner responses to pain; relationship satisfaction; empathy; catastrophizing; ambivalence over emotional expression; pain self-efficacy 


\section{Introduction}

Although many consider genital pain in women to be a private and personal condition, it is not one that occurs in isolation: women's intimate partners are affected too. Genital pain is a common condition that can impair the sexual, relational, and psychological health of women and their partners [1-5]. Prevalence estimates range from $6.5 \%-45 \%$ in older women and from 14$34 \%$ in younger women [6]. In one study, $20 \%$ of sexually active adolescent girls reported vulvo-vaginal pain during intercourse lasting over six months [7]. Genital pain can result from underlying physical pathologies (e.g., endometriosis, interstitial cystitis), genital infections (e.g., candidiasis, herpes, bacterial vaginosis), or from events such as childbirth and menopause [6]. Pain can also be located further into the vaginal canal, causing a deeper pain during intercourse. In many cases, genital pain is diagnosed as vulvodynia - a burning pain, for which there are no relevant physical findings. According to the International Society for the Study of Vulvovaginal Disease (ISSVD), vulvodynia can be localized, which involves a portion of the vulva, or generalized, which involves the entire vulva [8]. With a prevalence of $12 \%$ in the general population, the most common subtype of localized vulvodynia is provoked vestibulodynia (PVD), which is characterized by a burning pain upon pressure to the vulvar vestibule or attempted vaginal penetration in sexual and non-sexual situations [8].

Genital pain implicates several etiologic pathways and is multifactorial: it involves a complex interplay of biological, psychological, and social factors [1]. The primary interference of genital pain is to the sexuality and intimate relationship of the woman with pain, suggesting an inherently interpersonal aspect to this condition. Specifically, partners may trigger the pain during sexual activity, observe the woman's and have their own emotional and behavioral reactions to the pain, and also suffer negative consequences to their sexual and intimate 
relationship. Although there is now sufficient evidence to ascertain that specific characteristics of romantic relationships are associated with pain and pain-related disability [9], and clinical models of sexual function focus on the importance of relationship characteristics such as intimacy (e.g. [10]), dyadic correlates of pain and sexuality have not been widely studied in comparison to other psychosocial factors [11].

Recent studies point to the important role of the romantic relationship in women's experience of genital pain and its consequences for both members of the affected couple. Women suffering from genital pain indicate that it negatively affects their ability to feel close and to show affection to their partners [12]. In qualitative reports, they also report feeling guilt, shame and inadequacy as a partner [13] and a strong fear of losing or disappointing their spouse because of the pain $[14,15]$. Such findings illustrate the relationship strain experienced by women due to the pain, as well as how relational stressors may lead to greater pain and distress. However, the partner can also be a positive force: in one study women noted that having an understanding partner is the most helpful component in their ability to cope emotionally with their pain [16]. Similarly, partner encouragement of women's efforts to cope with their genital pain has been associated with less pain and greater sexual satisfaction and sexual functioning [17, 18]. Recent theoretical models and empirical studies have begun to shed light on the specific role of relationship processes in the experience of genital pain and the psychosexual adjustment of couples struggling with this debilitating condition.

\section{Theoretical models for the role of the partner}

\section{Operant learning model}

Fordyce [19] originally proposed an operant learning model as an explanation for the role of the significant other in the maintenance of pain. He suggested that pain behaviors such as 
verbal complaints, are influenced by environmental contingencies that serve to reinforce and perpetuate these overt expressions of distress. The partner, as the primary witness of these displays of suffering, may thus inadvertently become a powerful reinforcing agent and contribute to increased pain and disability.

Block, Kremer and Gaylor [20] first investigated the specific effects of couple interactions on overt displays of pain behavior in a sample of 20 patients with chronic pain. Those who perceived their partners to be solicitous (i.e., demonstrating sympathy, attention, and support) reported higher levels of pain in a partner-observing condition than in a neutral-observer condition. Along the same lines, Paulsen and Altmaier [21] found that patients whose partners were supportive exhibited more pain behavior during a physical examination in the partnerpresent compared to the partner-absent condition. These findings show that the experience of pain is influenced by the patient's perception of partner responses, as well as by the presence or absence of the partner. They also highlight the role of partner solicitousness as a type of response that may contribute to increased pain intensity.

In an experimental study involving direct observation of couple interactions, Romano et al. [22] found that partner solicitous behaviors were more likely to precede and follow nonverbal pain behaviors, whereas nonverbal pain behaviors were less likely to follow spouse aggressive behaviors. These findings suggest that not all types of partner responses are associated with increased pain behaviors, but rather that solicitousness appears to be the key variable. Importantly, they show that partner solicitousness is antecedent to pain behaviors.

However, other studies have shown that significant others' negative responses (i.e., demonstrations of anger, disappointment) also influence the experience of individuals with chronic pain. Waltz, Kriegel, and van' T Pad Bosh [23] found that patient evaluations of partner 
negative behaviors toward their pain (avoidance and critical remarks) were related to greater pain intensity. In addition, partner negative responses regarding patient pain behaviors, as rated by partners and patients, have been shown to be related to greater psychosocial difficulties and painrelated functional deficits [24-29]. The most consistent finding has been that partner negative responses are associated with increased patient psychological distress - depressive symptoms in particular [30]. When genital pain is experienced during sexual activity, it occurs in the presence of the partner, in a context of mutual vulnerability. This setting could contribute to stronger cognitive and affective reactions in each member of the couple, whereby both partner negative and solicitous responses and patient appraisals might be heightened, with subsequent consequences for women's pain and the psychosexual adjustment of the couple.

\section{Cognitive-behavioral and communal coping models}

Operant models of chronic pain have been criticized for being overly restrictive in their conceptualization of pain and neglecting the various biopsychosocial interactions that take place in most pain problems. Turk and Fernandez [31] have underscored the importance of integrating patients' appraisals, attributions and expectancies with actual reinforcement contingencies. This cognitive-behavioral perspective suggests that patients' pain-related beliefs and attributions will impact emotional and behavioral responses to pain, as well as influence the effect of the social environment [32]. In line with this theoretical conceptualization, recent empirical research has highlighted the limits of the operant model. Indeed, pain behaviors and certain types of coping strategies have been found to increase also in the presence of a neutral observer, where past reinforcing experiences could not have taken place [33]. In addition, coping strategies are not overt, implying that they would be less amenable to selective reinforcement. Sullivan et al. [34] have proposed an alternative to the operant model - the Communal coping model (CCM). This 
model purports that certain individuals will behave in a manner that will increase the probability that a stressful situation is managed interpersonally. They suggest that exaggerated displays of pain behavior in the presence of others, or pain catastrophizing, may serve communication and coping purposes, as a means to elicit empathic responses, assistance, or to maximize proximity [34]. It is plausible that such a model may partly explain the contribution of relationship factors in genital pain to the experience of persistent pain and psychosexual impairment, particularly in the context of an activity as intimate as intercourse. Specifically, increased verbal and nonverbal pain behaviors, such as pain catastrophizing, could serve to elicit partner solicitousness, which in turn could contribute to maintain proximity in spite of the challenge to physical intimacy posed by the pain. It is thought that partner solicitousness could function as a mediator of the relation between catastrophzing and the experience of pain (e.g. [35]). However, the empirical data to support this assertion are still scarce, and one study in a sample of women with genital pain supported a different direction for these associations: catastrophizing mediated the association between partner solicitousness and women's pain intensity [36]. Most of the research conducted so far on the CCM has not included the partners of pain patients, and it has relied almost exclusively on cross-sectional designs - two important limitations.

\section{Intimacy Models}

While both operant and cognitive-behavioral models have heightened our understanding of the social context of pain, they have been criticized for their restricted conceptualization of interpersonal processes [37-39]. In focusing on the cognitions and behaviors that encompass pain communication and partner responses to pain (e.g., support seeking, reinforcement), these models fail to account for the affective dimension of pain-related communication [38]. Exploratory factor analyses suggest that partner validation and invalidation, which are two core 
components of intimacy models of chronic pain, tap into emotional responses that are not necessarily present in other types of behaviorally-oriented partner responding (e.g., solicitous and distracting responses; [37]). The disruption to the sexual relationship experienced by couples struggling with genital pain may affect the ways they build intimacy with one another, highlighting the potential importance of intimacy models for this condition.

The Interpersonal Process Model of Intimacy posits that intimacy develops when an individual discloses his or her personal thoughts and feelings, and based on the degree of empathy perceived in the partner's response, feels validated, understood, and supported [40]. Intimacy models have been empirically supported in chronic pain populations (e.g., [41]), and recently in women with genital pain [39]. According to observational [41] and self-report studies [42], emotional disclosure of pain-related distress is a common component of pain-related communication in individuals with chronic pain, and is associated with greater pain severity, anxiety, depression, and pain catastrophizing [41].

Another model of intimacy that focuses more exclusively on the role of empathy, proposes that couples' empathic responses directly influence their emotional regulation with regard to the pain and psychosocial adjustment $[43,44]$. For example, prior research has demonstrated a positive relationship between spousal validation and relationship satisfaction in chronic pain couples, whereas couples' invalidating responses were related to higher pain intensity, greater depression, and lower relationship satisfaction [37, 44, 45].

In genital pain, women's emotional disclosures may be an attempt to re-build the intimacy that they fear they have lost in their sexual relationship with their partner. In turn, a more empathic partner may facilitate the woman's emotional regulation by creating a validating emotional climate in which both partners are better equipped to process and cope with the pain- 
related stressors they are experiencing (e.g., decreased frequency of sexual intercourse), leading to improved pain and psychosexual adjustment. In contrast, a less empathic partner who exhibits more invalidating responses, may disrupt a couple's ability to regulate their emotions, hindering the intimate connection between partners and interfering with the couple's adaptive coping strategies, likely resulting in greater pain and psychosexual impairment $[38,44]$.

Further, "empathic accuracy", or the partner's ability to understand the pain-related thoughts and feelings of the person with pain, may be an important component to generating feelings of validation [46]. Even partners' well-intentioned attempts to empathically respond may be perceived as invalidating if they in fact misinterpret the person's pain-related disclosures, which could exacerbate the distress experienced by both members of the couple. Relative to other chronic pain populations, the shared circumstances in which women experience genital pain underscores the relevance of intimacy and empathy conceptualizations, although research in this domain has just begun.

\section{Interpersonal correlates of female genital pain}

\section{Relationship Satisfaction}

The intimate context within which women experience genital pain has led researchers to question whether the impact of this condition extends to the couples' relationships more globally. After all, sexual and relationship satisfaction are strongly correlated constructs [47] suggesting an inherent degree of interdependence.

A recent systematic review [48] examined whether PVD and other heterogeneous forms of vulvar pain negatively impact women and partners' relationship satisfaction. The majority of controlled, quantitative studies suggest that women with genital pain and their partners do not experience lower relationship satisfaction when compared to control groups or scale norms on 
validated measures of relationship adjustment [5, 49-56]. However, some studies have found significantly lower relationship adjustment in women with genital pain compared to controls [53, 56, 57]. Moreover, qualitative studies highlight the remarkable degree of stress that genital pain can place on women in romantic relationships, such as feeling like an inadequate partner and fearing the loss of one's partner $[13,58]$.

Researchers have also studied whether relationship satisfaction is associated with the intensity of genital pain itself. Associations between greater genital pain intensity and greater relationship difficulties (e.g., conflict, stress) have been documented [59-61]. While Meana, Binik, Khalife, and Cohen [5] reported that greater relationship satisfaction was associated with women's lower pain during intercourse, more recent studies have failed to replicate this finding and have found no significant association between relationship satisfaction and women's genital pain intensity (e.g., [53, 54, 62, 63]). Still, several specific interpersonal variables (e.g., partner responses, intimacy, attachment) have demonstrated important associations with fluctuations in pain and psychosexual outcomes for both partners [17, 18, 39, 63, 64].

Overall, the association between genital pain and relationship satisfaction remains unclear [48]. Inconsistent and/or methodological limitations (e.g., quantitative versus qualitative methods, validated versus non-validated questionnaires, lack of control groups) have contributed to the inconclusive state of this literature. Smith and Pukall [48] suggest that the sexual relationship, rather than the global relationship, is specifically impacted by genital pain, and that extant global measures of relationship adjustment do not adequately capture this particular effect. Moreover, findings from qualitative studies that detail the severe strain that genital pain imposes on the romantic relationship suggest that it may not be relationship adjustment (i.e., interactions and processes that contribute to a functional relationship; [65]) that is impacted by this condition, 
but rather, aspects of relationship "quality" that may speak to a fundamental feeling of insecurity in the relationship (e.g., trust, commitment, confidence in one's role as a sexual partner/provider; $[58,66])$. Thus, it will be important for researchers to tease apart the elements of the romantic relationship (e.g., satisfaction, adjustment, or quality) that may truly be affected in genital pain populations.

\section{Partner responses to painful intercourse}

Of the interpersonal factors associated with women's genital pain experience, partner responses to women's pain have received the most attention. Partner responses can be solicitous (providing attention and sympathy), negative (demonstrations of hostility and frustration), and facilitative (encouraging adaptive coping). For example, in genital pain, a solicitous response could be a partner offering assistance or comfort, or suggesting cessation of all sexual activity, a negative response would be a partner expressing anger or frustration, and a facilitative response would be a partner expressing love or happiness that the woman is engaging in any sexual activity. In a series of cross-sectional studies, Rosen and colleagues found that higher solicitous partner responses - as perceived by women and male partners - were associated with greater pain intensity during intercourse, and that this association was mediated by greater pain catastrophizing [36, 67]. Higher solicitous and lower negative responses were associated with greater sexual satisfaction, and this association was mediated by greater relationship satisfaction $[36,67]$. In contrast, greater facilitative responses were associated with lower pain and greater sexual satisfaction. Further, a recent dyadic daily experience study showed that a woman's sexual functioning improved on days when she perceived greater facilitative, lower solicitous, and lower negative male partner responses, and when her male partner reported lower solicitous 
responses. A man's sexual functioning was poorer on days when he reported greater solicitous and negative responses [17].

Rosen and colleagues interpreted these findings in light of both cognitive-behavioral and intimacy models of chronic pain. Greater solicitous and negative partner responses may positively reinforce couples' pain behaviors (e.g., avoidance) and maladaptive cognitiveaffective appraisals of the pain (e.g., catastrophizing, feelings of guilt and anxiety), leading to more pain and impairment. In contrast, facilitative responses may negatively reinforce these factors, leading to less pain and better adjustment. The reinforcement of avoidance is especially important because women and couples affected by genital pain are frequently avoidant of all sexual activities as well as intimate touching (e.g., kissing) [68], perhaps due to a fear that nonpain activities will still lead to painful intercourse. Extensive avoidance of intimate partner contact may negatively impact other aspects of the relationship, such as feelings of intimacy and closeness, and have cumulative effects over time. Consistent with intimacy models, negative responses may convey a lack of empathy for the woman's experience, which could interrupt women's emotional regulation, reduce her adaptive coping, and ultimately lead to greater pain and poorer psychosexual adjustment. In contrast, facilitative responses may foster greater couple intimacy, thereby enhancing pain coping and allowing the couple to focus on more pleasurable aspects of the sexual interaction, leading to improved pain and psychosexual functioning [17].

\section{Intimacy}

Intimacy is considered to be a core component of relational processes between romantic partners, and has demonstrated important associations with sexual function, sexual satisfaction, psychological distress, and relationship satisfaction in both non-clinical and clinical couples, including cancer, chronic pain, and sexual dysfunction populations (e.g., [69-73]). Sexual 
intimacy, while positively related to broader relationship intimacy, refers to feelings of intimacy in the context of sexual experiences [74]. Sexual intimacy has been found to be conceptually distinct from relationship intimacy, and is a stronger predictor of sexual satisfaction than relationship intimacy in community samples [74].

Surprisingly, only one study has examined intimacy, defined by self-disclosure and empathic partner responding, in women with genital pain. In a cross-sectional study of women with PVD and their partners, controlling for partner's intimacy ratings, women's greater sexual intimacy was associated with their higher sexual satisfaction, sexual function, and pain selfefficacy (i.e., confidence in their ability to cope with the pain; [39]. Additionally, women's greater relationship intimacy was associated with their higher sexual function. Consistent with intimacy models of chronic pain [38], greater intimacy may buffer against the negative psychosexual consequences that are prevalent for women with genital pain, by assisting in women's emotional regulation (e.g., stress management) of their pain and adaptive pain coping, leading to improvements in their sexual well-being. The sexually intimate context in which the pain is most often elicited may make intimacy, or the aspects of couple interaction that foster intimacy (e.g., open, constructive, and supportive communication), important targets of intervention for couples struggling with this debilitating condition.

\section{Attachment}

Attachment patterns, which develop in infancy based on the security and stability of the infant-caregiver relationship, manifest in adulthood by influencing individuals' attachment needs and behaviors (e.g., intimacy versus independence) in romantic relationships [75]. Insecure attachment styles, characterized by high attachment anxiety (i.e., anxiety about rejection or the loss of a partner) and/or high avoidance (i.e., emotional distancing from one's partner), are 
associated with poorer sexual function, satisfaction, and differences in motivation for sex and the frequency of sexual activity in community samples of both men and women [76]. Given that genital pain is elicited in the context of a sexual and intimate relationship, researchers have proposed that attachment theory may further our understanding of the pain experience and sexual well-being of women suffering from genital pain $[64,77]$.

Two recent studies in genital pain populations have examined the role of women's attachment styles in their pain and sexual adjustment $[64,77]$. Granot et al. [77] found a higher incidence of insecure attachment styles in women reporting pain during intercourse compared to a no-pain control group. When examining anxiety and avoidance dimensions of attachment specifically, they found that women with genital pain had higher attachment avoidance than control women, but did not differ in their attachment anxiety. Furthermore, attachment avoidance was positively associated with pain intensity during intercourse. These findings suggest that the pain associated with sexual activity may be related to women distancing themselves from their partner rather than seeking their partner's closeness for fear of losing them. In a sample of women with PVD and their partners, Leclerc et al. [64] found that controlling for partners' level of attachment, women's higher attachment anxiety and attachment avoidance were associated with their lower sexual satisfaction, and that women's higher attachment avoidance was associated with their lower sexual function. Moreover, sexual assertiveness was found to fully mediate the relationship between attachment anxiety and sexual satisfaction in women, and between attachment avoidance and both sexual satisfaction and function in women. These results suggest that insecure attachment styles may negatively impact sexual outcomes in PVD by hindering women's ability to be sexually assertive with their partners. 
It may be worthwhile to expand our theoretical conceptualizations of genital pain to account for attachment patterns. As applied to the context of genital pain, the attachmentdiathesis model of chronic pain [78] proposes that the experience of genital pain triggers attachment-related cognitive appraisals of pain, such as pain self-efficacy, which is known to predict pain intensity and sexual function in women with genital pain (e.g., [79, 80]). In turn, attachment-related cognitive appraisals may influence women's behavioral and emotional responses to the pain, such as emotional disclosure and coping behavior, thus affecting women's pain, sexual, and psychological adjustment. Furthermore, attachment is proposed to moderate and/or mediate the effect of these appraisals and responses on adjustment [78].

\section{Partner correlates of female genital pain}

As part of the growing body of research into interpersonal aspects of genital pain, there is an increasing interest in the association between partners' cognitive-affective factors and women's pain and sexual experience. Ambivalence over emotional expression (AEE) refers to the individual's comfort in expressing emotion independent of other expressive qualities the person may possess [81]. For example, AEE aims to capture what lies under the surface of one's expressiveness - whether the person is expressive but wishes to disclose less, or has trouble expressing him or herself but desires to be more comfortable sharing. The affective construct of AEE is conceptualized as a means of emotional regulation in an interpersonal context of emotional expression. In research with other pain populations, greater AEE was associated with higher reports of pain, dysfunction, and psychological distress [82], and decreased life satisfaction in partners [83]. Recently, AEE was examined in a cross-sectional study of 254 women with genital pain and their partners [84]. Couples in which both members scored low on AEE reported higher sexual satisfaction and sexual functioning, higher dyadic adjustment, and 
fewer depressive symptoms when compared to couples where one or both members reported high AEE. In the context of genital pain, being more ambivalent about one's emotional expression may contribute to greater discomfort and difficulties when communicating about sexuality, making it more difficult for the couple to navigate adaptive coping strategies (e.g., expansion of sexual repertoire) [84]. In line with this notion, higher sexual assertiveness in partners has been associated with higher sexual function among women with genital pain, suggesting that being sexually assertive is important to help these couples navigate their shared sexuality [64]. Given that poor communication has been associated with impaired sexual satisfaction among non-clinical samples $[85,86]$, as well as greater pain in other chronic pain populations (e.g., [41]), AEE or the expression of emotions relating to sex and pain may be an important clinical target for assisting couples with genital pain.

In addition to the importance of the couple's emotional expression to the navigation of genital pain, cognitions or thoughts surrounding pain are also integral players. Higher levels of catastrophizing, and lower levels of pain self-efficacy among women with genital pain are significantly associated with increased intercourse pain, while higher reports of pain self-efficacy are associated with women's better sexual functioning [79]. Stemming from these findings, researchers investigated the impact of these same negative pain-related cognitions as perceived by the partner in a sample of couples $(n=179)$ in which the woman was experiencing introital dyspareunia [87]. They found that partner catastrophizing contributed a significant amount of variance to the woman's reported pain intensity, but partner variables did not contribute to women's sexual function or satisfaction. When partners catastrophize about the pain, they may be contributing to a dialogue that places greater focus on the pain [87]. Findings are also 
consistent with the robust relationship that catastrophizing has with pain and reflects an independence of pain-related cognitions from sexual function [86].

\section{Impact of genital pain on the (male) partner}

Despite an increasing appreciation of the interpersonal context of genital pain, there are few studies that focus on the impact of women's genital pain on the male partner. In one of the first studies to examine the influence of genital pain on the health and wellbeing of both the woman and her partner, the majority of women reported that their partner had been greatly affected by their genital pain symptoms [88]. Specifically, male partners reported more depressive symptoms when compared to a control group of healthy men (mild to severe depressive symptoms present among $33.3 \%$ compared to $7.6 \%$ in controls). Nylanderlundqvist and Bergdahl [88] suggested that the partners' increased depressive symptoms might indicate relational problems. In contrast, partners from another sample of couples experiencing genital pain did not report increased psychological or relational distress when compared to population norms [49]. Determining the impact of genital pain on the partner's quality of life represents an area for continued investigation.

A limited number of studies have examined associations between certain psychological and interpersonal variables and the relational and psychosexual adjustment of the male partners of women with genital pain. As noted previously in this review, greater partner-reported solicitous and negative responding to the woman's pain has been associated with poorer partner sexual functioning [17]. Jodoin and colleagues [4] examined whether partners' pain attributions regarding women's genital pain were associated with partners' relationship satisfaction, sexual functioning, sexual satisfaction, and psychological distress. When male partners made negative attributions about the pain (e.g., saw it as the woman's responsibility and as an internal, global 
and stable problem) in the presence of higher pain intensity as reported by the woman, partners reported greater psychological distress. Additionally, greater uses of internal and global attributions were associated with partners' lower relationship satisfaction, and global and stable attributions were related to lower partner sexual satisfaction. Partner's negative attributions may contribute to a distressing personal understanding of the woman's pain. A view of the pain that incorporates more elements of helplessness may also make it more difficult for the partner to contribute to active and adaptive coping related to women's genital pain [4]. This explanation is consistent with dyadic research conducted with other chronic pain populations. For example, in a study of people with chronic back pain and their partners, partners' greater helplessness, catastrophizing, and symptoms of anxiety were significantly associated with their greater invalidation of the patient's pain-related disclosures [41]. Together these findings suggest that cognitive-behavioral therapy may help the partner and the couple develop more adaptive attributions for their pain, which could improve their pain coping, with subsequent benefits to relationship satisfaction, sexual functioning, sexual satisfaction, and psychological distress [4]. In sum, the ways in which partners respond to and attempt to understand the genital pain may play an important role in partners' subjective experience, both psychologically and sexually, as well as interact with the woman's experience to either improve or burden their shared and individual functioning.

\section{Conclusions and future directions}

Including both members of the couple in studies of genital pain is of growing importance in light of the widespread appreciation for the social context of pain, and in line with clinical models that underscore relationship characteristics in sexual functioning [10]). The research findings included in this review have underscored that (1) genital pain is a condition that affects 
the psychological, relational, and sexual functioning of both members of the couple, (2) interpersonal variables affect women's pain and the psychosexual adjustment of the couple, and (3) there may be a reciprocal interaction between the woman and partner's experience of genital pain and its consequences. Further progress requires researchers to consider theoretical, methodological, and clinical advancements in order to improve understanding of the role of relationship processes in female genital pain.

Theoretically, there have been recent calls to move beyond strictly intra-individual and cognitive-behavioral models of chronic pain, and genital pain, in order to incorporate interpersonal influences $[1,89]$. Such advances in conceptualization and corresponding research are all the more pertinent in the context of genital pain given that the pain interferes with the sexual and overall intimate relationship. Future research directed toward how operant, cognitivebehavioral, intimacy, and potentially attachment models may or may not be integrated into an overarching framework will be useful for improving our understanding of interpersonal factors in chronic pain more generally, and genital pain in particular. Further, studies of mediation will be essential to help clarify the mechanisms underlying theoretical models.

Research methodologies will need to be expanded to better capture the dynamic nature of couple interactions. Dyadic daily experience studies reduce recall biases and take into account the unique thoughts, emotions, and behaviors that vary on a daily basis, such as mood, relationship conflict, and stress, and may influence changes in day-to-day pain and sexual interactions. Daily experience designs also afford the opportunity to examine lagged-day effects, thereby providing greater support for the temporal order of associations. Given the inherent biases of self-report methodologies, observational studies are another important avenue for further research. Observational studies may be a more appropriate methodology for examining 
certain interpersonal factors, such as couple intimacy. Such studies are better able to capture actual couple behaviours as they occur, although the ecological validity is a potential limitation. Observing the disclosure-responsiveness exchange between partners may be important to understanding the sequential and/or reciprocal nature of intimacy in genital pain couples (e.g., does emotional disclosure directly precede a partner's validating response?). Similarly, longitudinal studies, in both the general population and clinical samples, are necessary to establish the temporal order of associations between interpersonal variables, pain, and psychosexual variables. Finally, all of the work reviewed in this paper included heterosexual couples only, and should be expanded to same-sex couples.

With regard to treatment, including the partner may reduce women's feelings of responsibility and guilt and enhance motivation for couples to work collaboratively toward improving their well-being. Targeted couple interventions should be developed and tested to examine their efficacy for women's genital pain conditions. A recent pilot study of cognitivebehavioral couple therapy for PVD demonstrated significant improvements from pre to posttreatment with regard to women's pain and sexual function, women and partners' sexual satisfaction, and several relevant pain coping variables (e.g., catastrophizing for both partners, and women's pain-self efficacy from both partners' perspectives) [90]. There is a great need for clinical trials to establish support for this treatment option, and to improve understanding of the underlying mechanisms that promote or interfere with couples' treatment outcomes. For example, do improvements in couple intimacy or communication patterns over the course of therapy contribute to treatment gains? And do such improvements exist above and beyond the effects of other cognitive-affective variables, such as decreased pain catastrophizing? Answering such questions would also shed light on the question of integrating the different theoretical models 
outlined in this review. Taken together, this review highlights the great value to be gained by including the partner in both research and clinical interventions aimed at improving the pain and psychosexual well-being of affected couples. 


\section{References}

- Denotes articles of major importance

-Denotes articles of importance

1. Bergeron S, Rosen NO, Morin M: Genital pain in women: Beyond interference with intercourse. Pain 2011, 152:1223-1225.

2. Desrochers G, Bergeron S, Landry T, Jodoin M: Do psychosexual factors play a role in the etiology of provoked vestibulodynia? A critical review. Journal of Sex and Marital Therapy 2008, 34:198-226.

3. Gates EA, Galask RP: Psychological and sexual functioning in women with vulvar vestibulitis. Journal of Psychosomatic Obstetrics and Gynaecology 2001, 22:221-228.

4. Jodoin M, Bergeron S, Khalife S, Dupuis MJ, Desrochers G, Leclerc B: Male partners of women with provoked vestibulodynia: Attributions for pain and their implications for dyadic adjustment, sexual satisfaction, and psychological distress. The Journal of Sexual Medicine 2008, 5:2862-2870.

5. Meana M, Binik YM, Khalifé S, Cohen D: Affect and marital adjustment in women's rating of dyspareunic pain. Canadian Journal of Psychiatry 1998, 43:381-385.

6. van Lankveld JJ, Granot M, Weijmar Schultz WC, Binik YM, Wesselmann U, Pukall CF, Bohm-Starke N, Achtrari C: Women's sexual pain disorders. The Journal of Sexual Medicine 2010, 7(1):615-631.

7. Landry T, Bergeron S: How young does vulvo-vaginal pain begin? Prevalence and characteristics in dyspareunia in adolescents. Journal of Sexual Medicine 2009, 6(4):927-935. 
8. Moyal-Barracco M, Lynch P: 2003 ISSVD terminology and classification of vulvodynia: A historical perspective. Journal of Reproductive Medicine 2004, 49:772779.

9. Kiecolt-Glaser JK, Newton TL: Marriage and health: his and hers. Psychological Bulletin 2001, 127(4):472-503.

10. Schnarch DM: Constructing the Sexual Crucible: An Integration of Sexual and Marital Therapy. New York: W.W. Norton \& Company; 1991.

11. Gatchel RJ, Turk DC: Psychosocial Factors in Pain: Critical Perspectives. New York: The Guilford Press; 1999.

12. Ponte M, Klemperer E, Sahay A, Chren MM: Effects of vulvodynia on quality of life. Journal of the American Academy of Dermatology 2009, 60:70-76.

13. Ayling K, Ussher JM: "If sex hurts, am I still a woman?" The subjective experience of vulvodynia in hetero-sexual women. Archives of Sexual Behavior 2008, 37:294-304.

14. Elmerstig E, Wijma B, Bertero RNT: Why do young women continue to have sexual intercourse despite pain? Journal of Adolescent Health 2008, 43:357-363.

15. Sheppard C, Hallam-Jones R, Wylie K: Why have you both come? Emotional, relationship, sexual and social issues raised by heterosexual couples seeking sexual therapy in women referred to a sexual difficulties clinic with a history of vulval pain. Sexual and Relationship Therapy 2008, 23(3):217-226.

16. Gordon AS, Panahian-Jand M, McComb F, Melegari C, Sharp S: Characteristics of women with vulvar pain disorders: Responses to a Web-based survey. Journal of Sex \& Marital Therapy 2003, 29 (Suppl. 1):45-58. 
17. $• \bullet$ Rosen NO, Bergeron S, Sadikaj G, Glowacka M, Delisle I, Baxter M: Impact of partner responses on sexual function in women with vulvodynia and their partners: A dyadic daily experience study. Health Psychology in press.

Authors used daily diary methods to examine the associations between partner responses and the sexual function of women with vulvodynia and their partners. Results indicate that facilitative and solicitous/negative responses may enhance and diminish sexual functioning, respectively. Results were interpreted according to both cognitivebehavioural and intimacy models of pain.

18. Rosen NO, Bergeron S, Glowacka M, Delisle I, Baxter M: Harmful or helpful: Solicitous and facilitative partner responses differentially predict pain and sexual satisfaction in women with provoked vestibulodynia. The Journal of Sexual Medicine 2012, 9:2351-2360.

19. Fordyce WE: Behavioral methods for chronic pain and illness. St. Louis: CV Mosby; 1976.

20. Block AR, Kremer E, Gaylor M: Behavioral treatment of chronic pain: variables affecting treatment efficacy. Pain 1980, 8(3):367-375.

21. Paulsen JS, Altmaier EM: The effects of perceived versus enacted social support on the discriminative cue function of spouses for pain behaviors. Pain 1995, 60(1):103110.

22. Romano JM, Turner JA, Friedman LS, Bulcroft RA, Jensen MP, Hops H, Wright SF: Sequential analysis of chronic pain behaviors and spouse responses. Journal of Consulting and Clinical Psychology 1992, 60(5):777-782.

23. Waltz M, Kriegel W, van't Pad Bosch P: The social environment and health in rheumatoid arthritis: marital quality predicts individual variability in pain severity. Arthritis Care and Research 1998, 11(5):356-374. 
24. Boothby JL, Thorn BE, Overduin LY, Ward LC: Catastrophizing and perceived partner responses to pain. Pain 2004, 109(3):500-506.

25. Cano A, Weisberg JN, Gallagher RM: Marital satisfaction and pain severity mediate the association between negative spouse responses to pain and depressive symptoms in a chronic pain patient sample. Pain Medicine 2000, 1(1):35-43.

26. Cano A, Gillis M, Heinz W, Geisser M, Foran H: Marital functioning, chronic pain, and psychological distress. Pain 2004, 107(1-2):99-106.

27. Cano A, Johansen AB, Franz A: Multilevel analysis of couple congruence on pain, interference, and disability. Pain 2005a, 118(3):369-379.

28. Kerns RD, Haythornthwaite J, Southwick S, Giller EL, Jr.: The role of marital interaction in chronic pain and depressive symptom severity. Journal of Psychosomatic Research 1990, 34(4):401-408.

29. Schwartz L, Slater MA, Birchler GR: The role of pain behaviors in the modulation of marital conflict in chronic pain couples. Pain 1996, 65(2-3):227-233.

30. Schwartz L, Jensen MP, Romano JM: The development and psychometric evaluation of an instrument to assess spouse responses to pain and well behavior in patients with chronic pain: the Spouse Response Inventory. The Journal of Pain 2005, 6(4):243-252.

31. Turk DC, Fernandez E: Pain : A cognitive-behavioural perspective. In: Cancer patient care: Psychological treatment methods. edn. Edited by Watson M. London: Cancer Research Campaign Psychological Medicine Research Group; 1992. 
32. Romano JM, Schmaling KB: Assessment of couples and families with chronic pain. In: Handbook of pain assessment (2nd ed). edn. Edited by Turk DC, Melzack R. New York: Guilford Press; 2001: 346-361.

33. Sullivan MJ, Adams H, Sullivan ME: Communicative dimensions of pain catastrophizing: social cueing effects on pain behaviour and coping. Pain 2004, 107(3):220-226.

34. Sullivan MJ, Thorn B, Haythornthwaite JA, Keefe F, Martin M, Bradley LA, Lefebvre JC: Theoretical perspectives on the relation between catastrophizing and pain. The Clinical Journal of Pain 2001, 17(1):52-64.

35. Buenaver LF, Edwards RR, Haythornthwaite JA: Pain-related catastrophizing and perceived social responses: Inter-relationships in the context of chronic pain. Pain 2007, 127(3):234-242.

36. Rosen NO, Bergeron S, Steban M, Lambert B: Provoked vestibulodynia: Mediators of the associations between partner responses, pain and sexual satisfaction. Archives of Sexual Behavior 2013, 42:129-141.

37. $\quad \cdot$ Cano A, Barterian JA, Heller JB: Empathetic and nonempathetic interaction in chronic pain couples. The Clinical Journal of Pain 2008, 24(8):678.

Authors employed behavioural coding and survey methods to study the relation between partner validation/invalidation and partner behavioural responses. Results provide empirical support for the theoretical distinction between empathic and behavioural partner responses.

38. Cano A, Williams ACC: Social interaction in pain: Reinforcing pain behaviors or building intimacy? Pain 2010, 149(1):9. 
39. • Bois K, Bergeron S, Rosen NO, McDuff P, Grégoire C: Sexual and relationship intimacy among women with provoked vestibulodynia and their partners: Associations with sexual satisfaction, sexual function, and pain self-efficacy. Journal of Sexual Medicine 2013, 10:2024-2035.

Authors applied the Interpersonal Process Model of Intimacy to examine the associations between relational and sexual intimacy and the pain and sexual adjustment of women with PVD. Results demonstrate the unique impact of women's perceptions of intimacy, controlling for partners intimacy, on female psychosexual adjustment in PVD.

40. Reis HT, Shaver P: Intimacy as an interpersonal process. In: Handbook of personal relationships: Theory, research, and interventions. edn. Edited by Duck S, Hay DF, Hobfoll SE, Ickes W, Montgomery BM. Oxford, England: John Wiley \& Sons; 1988: 367-389.

41. Cano A, Leong LE, Williams AM, May DK, Lutz JR: Correlates and consequences of the disclosure of pain-related distress to one's spouse. Pain 2012, 153:2441-2447.

42. Stephens MAP, Martire LM, K. C-SJ, A. DJ, Wojno WC: Older women with osteoarthritis and their caregiving husbands: Effects of pain and pain expression on husbands' well-being and support. Rehabilitation Psychology 2006, 51:3-12.

43. Fruzzetti AE, Iverson KM: Intervening with couples and families to treat emotion dysregulation and psychopathology. In: Emotion regulation in couples and families: Pathways to dysfunction and health. edn. Edited by K. SD, Simpson J, Hughes JN. Washington, DC: American Psychological Association; 2006: 249-267.

44. Leong LE, Cano A, Johansen AB: Sequential and base rate analysis of emotional validation and invalidation in chronic pain couples: Patient gender matters. The Journal of Pain 2011, 12(11):1140-1148. 
45. Johansen $\mathrm{AB}$, Cano $\mathrm{A}$ : A preliminary investigation of affective interaction in chronic pain couples. Pain 2007, 132:S86-S95.

46. Goubert L, Craig KD, Vervoort T, Morley S, Sullivan MJL, Williams AC, Cano A, Crombez G: Facing others in pain: the effects of empathy. Pain 2005, 118:285-288.

47. Byers ES: Relationship satisfaction and sexual satisfaction: A longitudinal study of individuals in long term relationships. Journal of Sex Research 2005, 42:113-118.

48. Smith KB, Pukall CF: A systematic review of relationship adjustment and sexual satisfaction among women with provoked vestibulodynia. Journal of Sex Research 2011, 48:166-191.

49. Desrosiers M, Bergeron S, Meana M, Leclerc B, Binik YM, Khalifé S: Psychosexual characteristics of vestibulodynia couples: Partner solicitousness and hostility are associated with pain. Journal of Sexual Medicine 2008, 5:418-427.

50. Smith KB, Pukall CF, Chamberlain SM: Sexual and relationship satisfaction and vestibular pain sensitivity among women with provoked vestibulodynia. Journal of Sexual Medicine 2013, 10:2009-2023.

51. Meana M, Binik YM, Khalifé S, Cohen D: Dyspareunia: Sexual dysfunction or pain syndrome? Journal of Nervous and Mental Disease 1997, 185:561-569.

52. Meana M, Binik YM, Khalifé S, Cohen DR: Biopsychosocial profile of women with dyspareunia. Obstetrics \& Gynecology 1997, 90:583-589.

53. Hallam-Jones R, Wylie KR, Osborne-Cripp J, Harrington C, Walters S: Sexual difficulties within a group of patients with vulvodynia. Sexual and Relationship Therapy 2001, 16:113-126. 
54. Reissing ED, Binik YM, Khalifé S, Cohen D, Amsel R: Etiological correlates of vaginismus: Sexual and physical abuse, sexual knowledge, sexual self-schema, and relationship adjustment. Journal of Sex and Marital Therapy 2003, 29:47-59.

55. Van Lankveld J, Weijenborg PTM, ter Kuile MM: Psychologic profiles of and sexual function in women with vulvar vestibulitis and their partners. Obstetrics and Gynecology 1996, 88:65-70.

56. Masheb RM, Brondolo E, Kerns RD: A multidimensional, case-control study of women with self-identified chronic vulvar pain. Pain Medicine 2002, 3:253-259.

57. Brauer M, ter Kuile MM, Laan E, Trimbos B: Cognitive-affective correlates and predictors of superficial dyspareunia. Journal of Sex and Marital Therapy 2009, 35:124.

58. Sheppard C, Hallam-Jones R, Wylie K: Why have you both come? Emotional, relationship, sexual, and social issues raised by heterosexual couples seeking sexual therapy (in women referred to a sexual difficulties clinic with a history of vulval pain). Sexual and Relationship Therapy 2008, 23:217-226.

59. White G, Jantos M: Sexual behavior changes with vulvar vestibulitis syndrome. Journal of Reproductive Medicine 1998, 43:783-789.

60. Schover LR, Youngs DD, Cannata R: Psychosexual aspects of the evaluation and management of vulvar vestibulitis. American Journal of Obstetrics \& Gynecology 1992, 167(3):630-636.

61. Sackett S, Gates E, Heckman-Stone C, Kobus AM-R, Galask R: Psychosexual aspects of vulvar vestibulitis. Journal of Reproductive Medicine 2001, 46:593-598. 
62. Reed BD, Haefner HK, Punch MR, Roth RS, Gorenflo DW, Gillespie BW: Psychosocial and sexual functioning in women with vulvodynia and chronic pelvic pain: A comparative evaluation. Journal of Reproductive Medicine 2000, 45:624-632.

63. Rosen NO, Bergeron S, Leclerc B, Lambert B, Steban M: Woman and partnerperceived partner responses predict pain and sexual satisfaction in provoked vestibulodynia (PVD) couples. Journal of Sexual Medicine 2010, 7:3715-3724.

64. Leclerc B, Bergeron S, Brassard A, Belanger C, Steben M, Lambert B: Attachment, sexual assertiveness and sexual outcomes in women with provoked vestibulodynia and their partners: A mediation model. Archives of Sexual Behaviour In press.

65. Sabatelli RM: Measurement issues in marital research: A review and critique of contemporary survey instruments. Journal of Marriage and the Family 1988:891-915.

66. Marriott C, Thompson AR: Managing threats to femininity: Personal and interpersonal experience of living with vulval pain. Psychology \& Health 2008, 23:243-258.

67. Rosen NO, Bergeron S, Leclerc B, Lambert B, Steben M: Woman and partnerperceived partner responses predict pain and sexual satisfaction in provoked vestibulodynia (PVD) couples. The Journal of Sexual Medicine 2010, 7:3715-3724.

68. White G, Jantos M: Sexual behavior changes with vulvar vestibulitis syndrome. The Journal of Reproductive Medicine 1998, 43:783-789.

69. McCabe MP: The interrelationship between intimacy, relationship functioning, and sexuality among men and women in committed relationships. Canadian Journal of Human Sexuality 1999, 8:31-38. 
70. McCabe MP: Intimacy and quality of life among sexually dysfunctional men and women. Journal of Sex and Marital Therapy 1997, 23:276-290.

71. Rubin H, Campbell L: Day-to-day changes in intimacy predict heightened relationship passion, sexual occurrence, and sexual satisfaction: A dyadic diary analysis. Social Psychological and Personal Science 2012, 3(2):224-231.

72. Manne SL, Sherman M, Ross S, Ostroff J, Heyman RE, Fox K: Couples' supportrelated communication, psychological distress, and relationship satisfaction among women with early stage breast cancer. Journal of Consulting and Clinical Psychology 2004, 72:660-670.

73. Schlesinger L: Chronic pain, intimacy, and sexuality: A qualitative study of women who live with pain. Journal of Sex Research 1996, 33:249-256.

74. Birnie-Porter C, Lydon JE: A prototype approach to understanding seuxal intimacy through its relationship to intimacy. Personal Relationships 2013, 20:236-258.

75. Bartholomew K, Horowitz LM: Attachment styles among young adults: A test of a four-category model. Journal of Personality and Social Psychology 1991, 61:226-244.

76. Stefanou C, McCabe MP: Adult attachment and sexual functioning: A review of past research. Journal of Sexual Medicine 2012, 9:2499-2507.

77. •Granot M, Zisman-Ilani Y, Ram E, Goldstick O, Yovell Y: Characteristics of attachment style in women with dyspareunia. Journal of Sex and Marital Therapy 2011, 37(1):1-16.

Authors examined attachment and somatization in a sample of women with dyspareunia using both continuous and categorical models of measurement. Results highlight the potential importance of attachment avoidance in the experience of pain during intercourse in women with dyspareunia. 
78. Meredith P, Ownsworth T, Strong J: A review of the evidence linking adult attachment theory and chronic pain: Presenting a conceptual model. Clinical Psychology Review 2008, 28(3):407-429.

79. Desrochers G, Bergeron S, Khalifé S, Dupuis M, Jodoin M: Fear avoidance and selfefficacy in relation to pain and sexual impairment in women with provoked vestibulodynia. The Clinical Journal of Pain 2009, 25:520-527.

80. Desrochers G, Bergeron S, Khalifé S, Dupuis M: Provoked vestibulodynia: Psychological predictors of topical and cognitive-behavioral treatment outcome. Behaviour Research and Therapy 2010, 48:106-115.

81. King LA, Emmons RA: Conflict over emotional expression: psychological and physical correlates. Journal of Personality and Social Psychology 1990, 58:864-877.

82. Porter LS, Keefe FJ, Lipkus I, Hurwitz H: Ambivalence over emotional expression in patients with gastrointestinal cancer and their caregivers: Associations with patient pain and quality of life. Pain 2005, 117:340-348.

83. Tucker JS, Winkelman DK, Katz JN, Bermas BL: Ambivalence over emotional expression and psychological well-being among rheumatoid arthritis patients and their spouse. Journal of Applied Social Psychology 1999, 29:271-290.

84. Awada N, Bergeron S, Hainault V, Steben M: To say or not to say: Dyadic ambivalence over emotional expression and its associations with pain, sexual function, distress, and dyadic adjustment of women with provoked vestibulodynia and their partners. under review.

85. MacNeil S, Byers ES: Role of sexual self-disclosure in the sexual satisfaction of longterm heterosexual couples. Journal of Sex Research 2009, 46:3-14. 
86. Montesi J, Conner B, Gordon E, Fauber R, Kim KH, Heimberg R: On the relationship among social anxiety, intimacy, sexual communication, and sexual satisfaction in young couples. Archives of Sexual Behavior 2012, 42:81-91.

87. -Lemieux A, Bergeron S, Steben M, Lambert B: Do romantic partners' responses to entry dyspareunia affect women's experiences of pain? The roles of catastrophizing and self-efficacy. The Journal of Sexual Medicine 2013, 10:2274-2284.

Authors examined the influence of partners' perceptions of pain self-efficacy and pain catastrophizing on the pain and sexual adjustment of women with dyspareunia. Results indicate that these partner cognitive variables may be more central to women's pain than sexual satisfaction and function.

88. Nylanderlundqvist E, Bergdahl J: Vulvar vestibulitis: Evidence of depression and state anxiety in patients and partners. Acta Derm Venereol 2003, 83:369-373.

89. Cano A, Williams AC: Social interaction in pain: Reinforcing pain behaviors or building intimacy? Pain 2010, 149:9-11.

90. Corsini-Munt S, Bergeron S, Rosen NO, Mayrand M, Hainault V, Awada N: Breaking the bell jar and including the partner when treating dyspareunia: A pilot study examining an innovative couple cognitive behavioral therapy for women with provoked vestibulodynia. In: International Society for the Study of Women's Sexual Health. New Orleans; 2013. 